\title{
ANÁLISE DE ACABAMENTO SUPERFICIAL EM ELEMENTOS PRÉ-FABRICADOS DE CONCRETO
}

\author{
E. R. BATISTON ${ }^{1}$, F. PELISSER ${ }^{2}$, R. WALNIE ${ }^{3}$ \\ ${ }^{1}$ Universidade Comunitária Regional de Chapecó, ${ }^{2,3}$ Universidade Federal de Santa Catarina \\ erbatiston@unochapeco.edu.br ${ }^{1}$
}

Submetido 05/09/2018 - Aceito 12/12/2018

DOI: $10.15628 /$ holos.2018.7693

\section{RESUMO}

O concreto pré-fabricado é um sistema construtivo que possibilita uma rápida execução, controle de qualidade e que facilita a racionalização da obra. Contudo o nível de defeitos e a qualidade do acabamento das peças são determinados qualitativamente através de inspeção visual e comparativos com padrões fotográficos. O objetivo deste trabalho é propor uma metodologia para a classificação da qualidade superficial das peças de concreto pré-fabricadas através da análise de imagens, reduzindo assim o caráter subjetivo e melhorando o processo na planta de produção. Para isto foram moldadas peças pré-fabricadas com concreto produzido em central. As imagens foram coletadas em pontos pré- definidos e analisadas individualmente por um software de analise de imagens, "image tool". Após um tratamento prévio nas imagens foi possível determinar a quantidade superficial de bolhas e defeitos, e a variação dimensional dos mesmos. Foi realizada então uma comparação com as imagens fornecidas pelo Guide for surface finish of formed concrete do qual foi compilada uma tabela de distribuição de tamanho e densidade de defeitos. O processo de classificação da qualidade superficial das peças de concreto pré-fabricados pôde assim ser obtido de maneira sistemática utilizando-se a análise de imagens.

PALAVRAS-CHAVE: Concreto pré-fabricado, Análise de imagens, Acabamento superficial.

\section{ANALYSIS OF SURFACE FINISH IN PREFABRICATED CONCRETE ELEMENTS}

\section{ABSTRACT}

The precast concrete is a building system that allows a rapid implementation and the quality control of the constructions and facilitates the rationalization of the building processes. The defect level and the quality of the construction finish is determined by a visual inspection and by comparison with photographic standards. The aim of this paper is to propose a methodology to classify the surface quality of the pieces of prefabricated concrete by image analysis, thereby reducing the subjective character and improving the process in the production plant. Framed with prefabricated concrete were produced in central and images were collected in pre-defined points and analyzed individually with an image analysis software, "image tool software". The images were treated by a digital manipulation of binarization using the tools provided by the software. After the treatment it was possible to determine the amount of bubbles, surface defects and its dimensional variation. It was then carried out a comparison with the images provided by the Guide for surface finish of formed concrete and a table with the size distribution and density of defects was compiled. The classification process of the surface quality of the pieces of precast concrete was obtained with a systematic way using the image análisis in this work.

KEYWORDS: precast concrete, image analysis, surface finish. 


\section{INTRODUÇÃO}

O concreto pré-fabricado é um sistema construtivo consolidado no mercado brasileiro por possibilitar uma rápida execução, controle de qualidade e facilitar a racionalização da obra. Segundo dados da ABCIC (2011) Associação Brasileira da Construção Industrializada de Concreto, o setor movimentou até o final de 2011 R\$ 5,5 bilhões, o que representa um crescimento de 15\% em relação ao ano de 2010. Quando comparados aos sistemas construtivos tradicionais, os sistemas pré-fabricados, como método construtivo, e o concreto, como material, têm inúmeras vantagens. Os produtos são feitos em fábricas, garantindo processos de produção mais eficientes e racionais, com trabalhadores treinados, repetição de tarefas e controle de qualidade constante (Pieri, 2007).

Por ser um processo industrializado possibilita um alto grau de inspeção. Contudo, no que diz respeito a acabamento superficial esta inspeção é qualitativa, mesmo a aparência sendo a primeira impressão que o consumidor tem da qualidade do produto. Todo processo de produção de pré-fabricados deve ter controle da qualidade da aparência das peças, e deve ser atribuída uma nota a esta característica para que sejam tomadas medidas para correção do problema (Terzian, 2005). Aspectos como quantidade de bolhas, manchas, fissuras, entre outros, devem ser controlados peça por peça. Dentre os vários defeitos possíveis nas peças de pré-fabricados podese destacar a presença de bolhas. As bolhas na superfície do concreto são ocasionadas por ar aprisionado e sujeira, mas o tipo de desmoldante e o material de que é feita a forma também influenciam no acabamento da peça (Annerel, 2007).

Para a atribuição de notas para qualificar o acabamento superficial das peças préfabricadas, Adam apud Terzinan (2005), recomenda que sejam utilizadas imagens de referência. Contudo este método é qualitativo e subjetivo, depende da destreza do técnico responsável pela qualificação.

As ferramentas de aquisição de imagens e os softwares de tratamento digital podem ser uma opção para a redução do fator subjetivo na qualificação de peças de pré-fabricados. Segundo Filho e Neto (1999) a etapa de aquisição tem como função converter uma imagem em uma representação numérica, neste processo dois elementos são importantes, dispositivo físico e o digitalizador. Hoje os equipamentos utilizados para o processo de aquisição de imagens são inúmeros e acessíveis, partindo desde microscopia ótica ou eletrônica, até as câmeras fotográficas digitais, escanners e mesmo celulares (Gonzales \& Woods, 2005). Uma vez aquisitada a imagem, esta pode passar por processamentos digitais que a tornarão um objeto matemático passível de quantificação, sendo a binarização um dos processos mais comuns e úteis para tratamento de imagens. Na binarização, a partir de uma imagem representada em níveis de cinza, escolhe-se um nível de corte, denominado de threshold, de maneira a dividir a imagem em dois grupos geralmente branco e preto, sendo uma fase para os objetos de interesse na análise, e outra para o fundo (Weidmman, 2005). 
Estudou-se neste trabalho a utilização de métodos de análise de imagens para quantificar o grau de acabamento das superfícies das peças de concreto pré-fabricado produzidos em uma empresa especializada da região de Criciúma, SC.

Foram aquisitadas imagens de peças produzidas pela indústria e aplicou-se uma metodologia de binarização e quantificação dos defeitos superficiais, esta metodologia possibilitou a identificação e qualificação das peças de maneira objetiva reduzindo a subjetividade da inspeção. Observou-se ainda que seria possível aprimorar a técnica para automatiza-la o que tornaria o serviço de inspeção muito mais rápido e preciso.

\section{MATERIAIS E PROGRAMA EXPERIMENTAL}

\subsection{Aquisição das imagens}

Para a aquisição das imagens foi utilizada uma câmera digital marca Sony modelo cybershot com resolução de 10,1 Mpixes. Esta câmera foi montada em um aparato para garantir a estabilidade, à distância e a iluminação adequada para a aquisição de imagens que atendam as necessidades de qualidade para a análize comparativa.

O aparato consiste de uma haste de tubo vazado com diâmetro de $75 \mathrm{~mm}$ e 1.30 metros altura com base reguladora de nível. Junto a haste vazada foi acoplado um guia na lateral externa para promover rigidez quanto ao deslocamento lateral. Na base que se desloca verticalmente foram acoplada 2 lâmpadas de led de potência de 1,5watts cada, como pode ser visto na Figura 1.

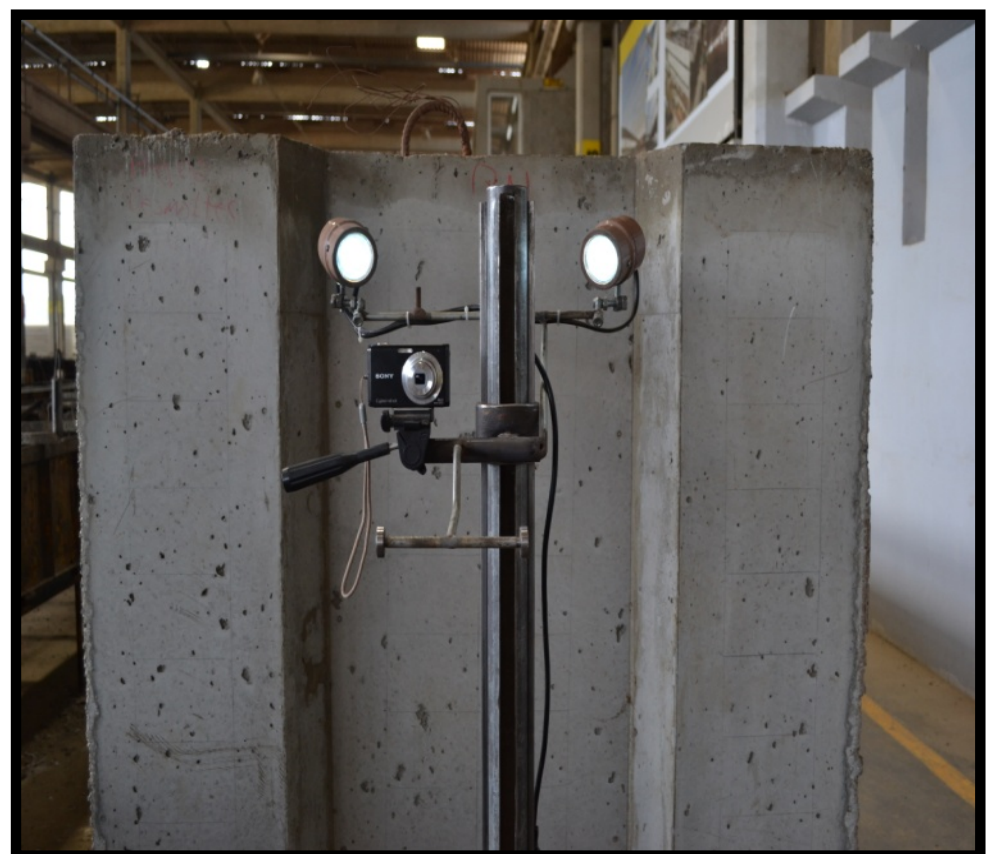

Figura 1 Aparato desenvolvido para obtenção das imagens. 
A câmera fotográfica foi acoplada a uma base com regulagem tanto horizontal quanto vertical, possibilitando ajustes na obtenção das imagens. Para limitação de distância entre a câmera e a peça foi acoplada uma haste medindo $20 \mathrm{~cm}$ de comprimento fixada a base que suporta a câmera (FIGURA 2).

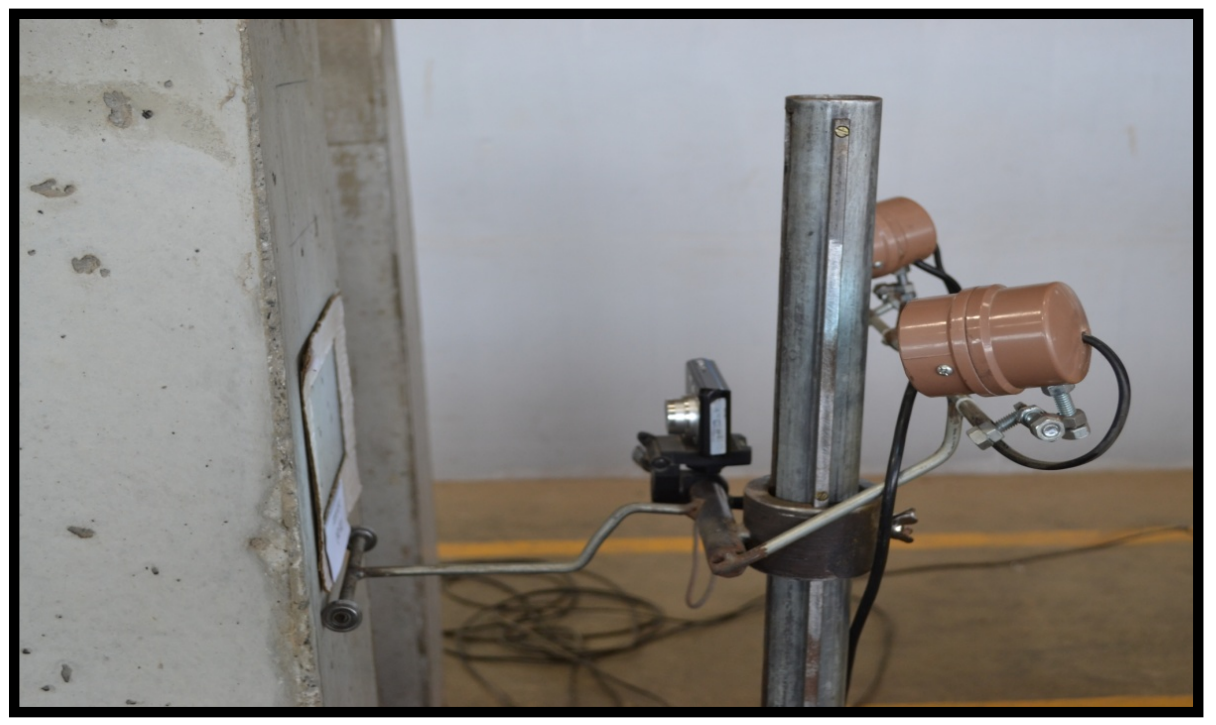

Figura 2 Vista lateral que mostra a barra de limitação do aparato em relação a peça.

Com objetivo de fornecer uma escala de referência foi acoplado a borda da imagem um enquadramento com papel milimetrado para posterior calibração das medidas no programa (FIGURA 3).

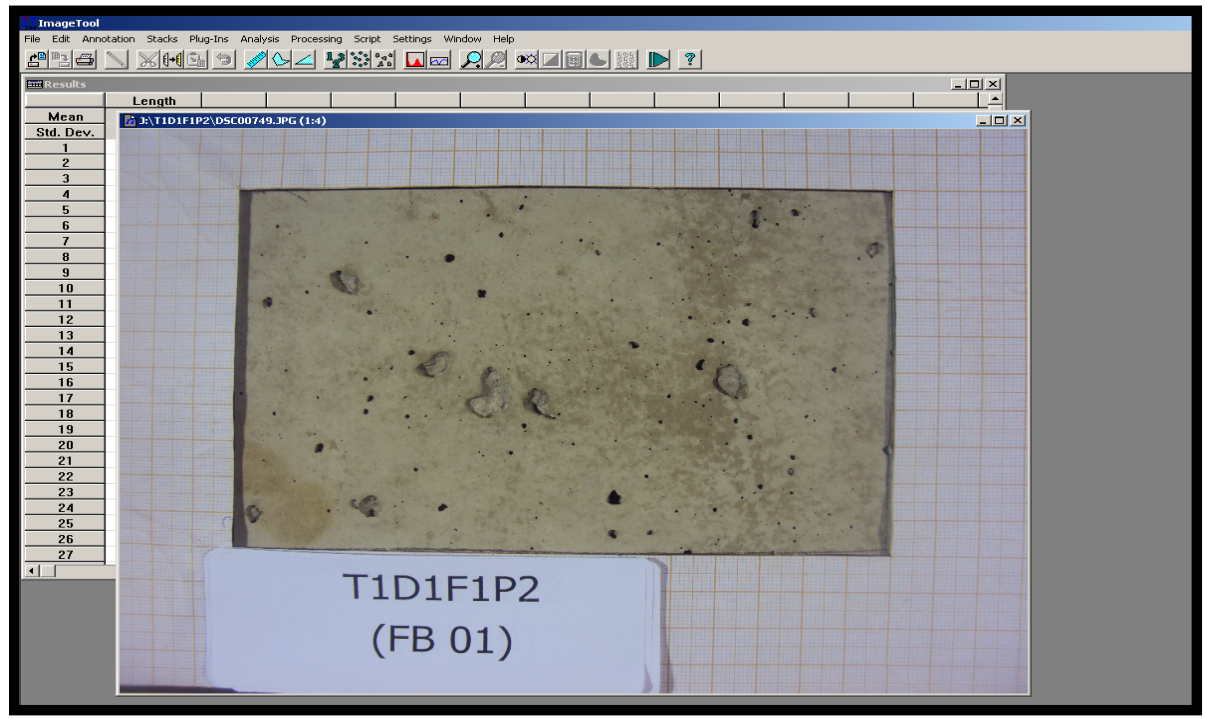

Figura 3 Interface do programa image tool

Para a análise computacional o programa utilizado foi o "image tool", é um programa gratuito e apresenta ferramentas apropriadas para o processo de análise das imagens. Este 
software foi desenvolvido pela University of Texas Health Sciense Center at San Antonio e está disponível gratuitamente na página eletrônica desta instituição ${ }^{1}$;

\subsection{Concretagem das peças}

Foram utilizados dois tipos de concreto para a moldagens de amostras para análise, com diferentes viscosidades, ambos concretos auto adensáveis (CAA) com fck de $50 \mathrm{MPa}$ moldados em central.

Após a mistura foram realizados ensaios de tronco do cone (slump flow) para a verificação da abertura, caixa $L$ para verificar o nivelamento do concreto, funil $V$ para verificar o tempo de escoamento. Para cada peça concretada foram moldados 3 pares de corpo de prova para ensaio de compressão simples. Os corpos de prova foram ensaiados a 1 dia, 7 dias e 28 dias respectivamente, a desforma ocorreu após 24 horas. Os resultados da caracterização dos concretos podem ser vistos na Tabela 1.

Tabela 1 Caracterização dos concretos utilizados.

\begin{tabular}{cccc|ccc}
\hline \multirow{2}{*}{ Traço } & \multicolumn{3}{c|}{ Ensaios no estado fresco } & \multicolumn{3}{c}{ Ensaios de Resistência (MPa) } \\
\cline { 2 - 7 } & $\begin{array}{c}\text { Slump Flow } \\
(\mathrm{mm})\end{array}$ & $\begin{array}{c}\text { Caixa L } \\
(\mathrm{cm})\end{array}$ & $\begin{array}{c}\text { Funil V } \\
(\mathrm{s})\end{array}$ & 1 Dia & 7 Dias & 28 Dias \\
\hline Menos Viscoso & 700 & $6 / 6$ & 7,49 & 26,45 & 43,32 & 52,35 \\
Mais Viscoso & 660 & $6 / 7$ & 10,59 & 27,36 & 44,87 & 54,21
\end{tabular}

\subsection{Análise das imagens}

Foram analisadas 6 fotos por peça, as imagens selecionadas foram escolhidas aleatoriamente, de forma que fossem amostras representativas do acabamento superficial das peças. Após serem escolhidas, as mesmas passaram por um processo de recorte digital. Todas as imagens a serem analisadas obtiveram medidas padronizadas de (2200x1400) pixel.

As imagens foram então exportadas para o image tool, onde foram analisadas individualmente. Primeiramente a imagem foi convertida para escala de cinza utilizando-se as ferramentas do programa. Após obter a imagem tratada realizou-se a calibração que define o tamanho em milímetros de cada pixel.

Passou-se então por um processo de binarização, utilizando-se seleção manual, que resultava em uma imagem onde as bolhas são pretas e o fundo branco. A imagem foi então submetida a um processo de filtragem que são ferramentas que auxiliam no destaque das bolhas, e na redução dos ruídos. Para este estudo a ferramenta que o proporcionou melhores resultados foi mediana $3 \times 3$, pois sua característica elimina ruídos que prejudicam a imagem sem deteriorar de forma significativa as bordas das bolhas.

\footnotetext{
${ }^{1}$ http://compdent.uthscsa.edu/ITDownload.asp
} 
Obteve-se assim uma tabela quantificando o percentual de área de bolhas que se concentra por faixa de diâmetro de análise.

Para propor uma classificação das peças através da análise de imagens, fez-se necessário a adoção de um padrão. Utilizou-se como referência o Guide for surface finish of formed Concrete (Hurd, 1999), foi selecionado um conjunto de peças que representam o acabamento descrito por este guia. Foi necessária a obtenção de imagens novas, pois a digitalização das imagens do guia não permitiu sua análise direta. Estas peças foram analisadas e o conjunto de tabelas correspondentes foi utilizado como padrão para a classificação das demais imagens conforme as Figuras 4 e 5.

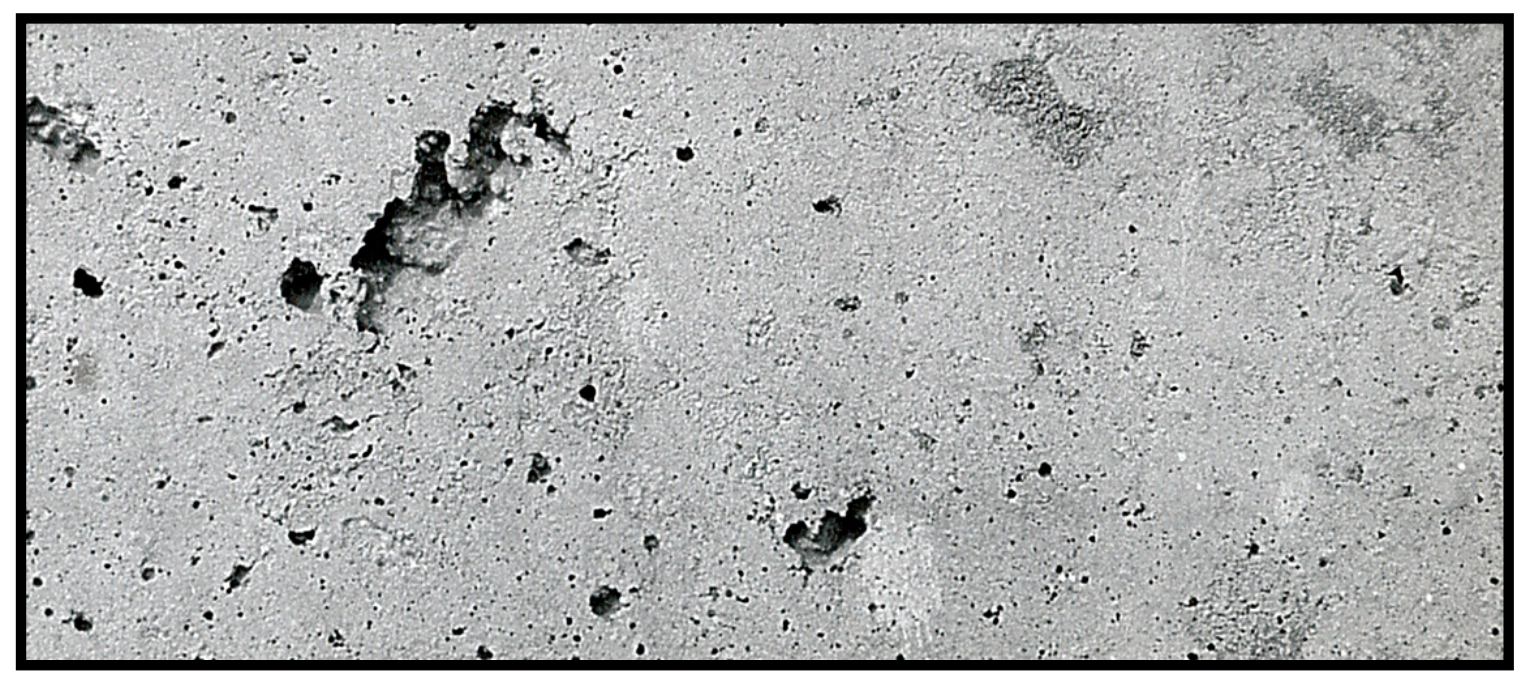

Figura 4 Figura referência retirada do Guide for surface finish of formed Concret [4].

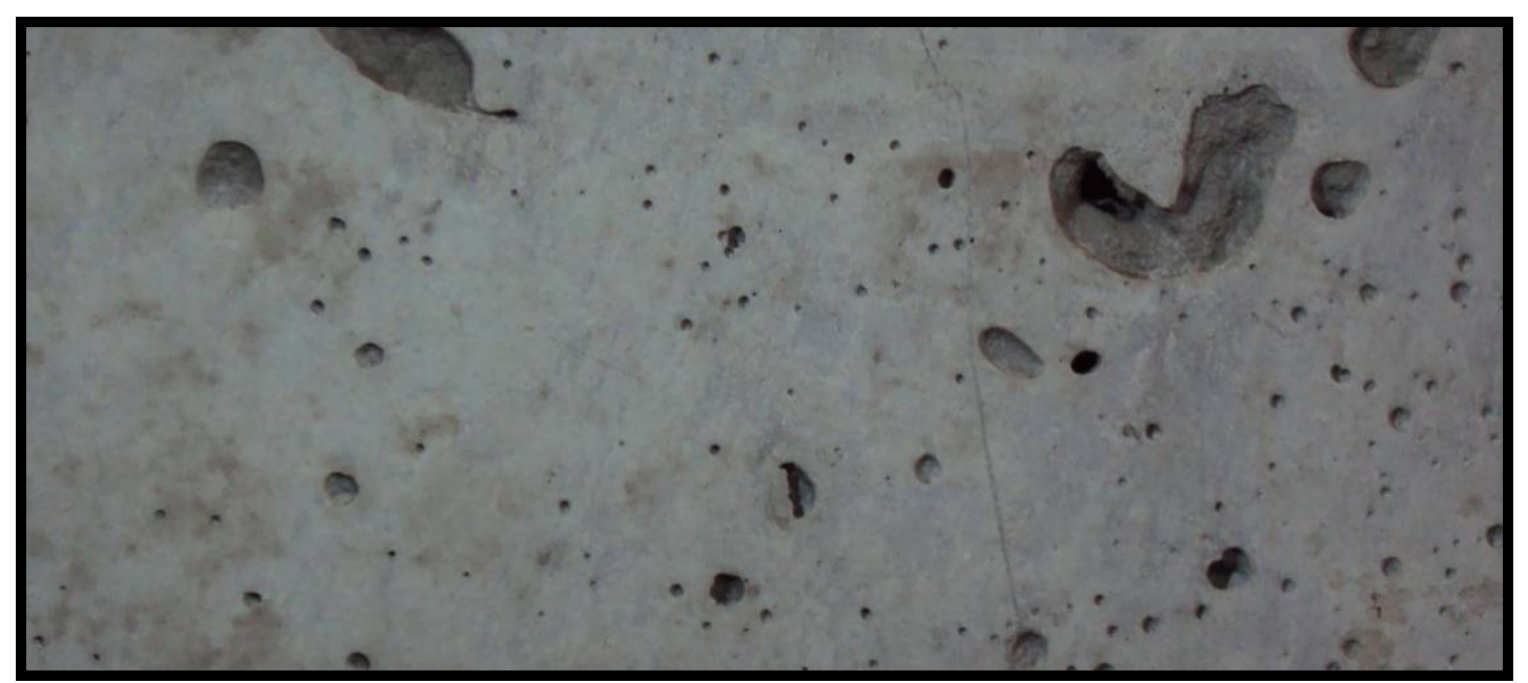

Figura 5 Imagem selecionada para obtenção dos padrões de acabamento a partir da análise de imagens. 


\section{RESULTADOS E DISCUSSÕES}

As imagens utilizadas como padrão foram analisadas e sua distribuição de bolhas superficial foi classificada por faixa de diâmetro, conforme Tabela 2.

Esta classificação foi realizada para as seis (06) categorias sugeridas por Hurd (1999) no Guide for surface finish of formed Concret, os resultados podem ser vistos na Figura 6. Nota-se que a distribuição de diâmetros é o parâmetro utilizado para classificação visual das peças, uma vez que o percentual total de área ocupada por defeitos pode variar de forma relativamente aleatória.

Tabela 2 Classificação de diâmetro de bolhas para a amostra classificada como excelente pelo Guide for surface finish of formed Concrete, (1999).

\begin{tabular}{|c|c|c|c|c|c|}
\hline $\begin{array}{c}\text { Faixa de } \\
\text { diâmetro }(\mathrm{mm})\end{array}$ & $\begin{array}{l}\text { Número } \\
\text { de } \\
\text { elementos }\end{array}$ & $\begin{array}{l}\text { Valor médio } \\
\qquad(\mathrm{mm})\end{array}$ & $\begin{array}{l}\text { Total de área por faixa } \\
\qquad\left(\mathrm{mm}^{2}\right)\end{array}$ & $\begin{array}{l}\text { Concentração } \\
\text { de bolhas (\%) }\end{array}$ & Std. Dev \\
\hline $0.00-1.00$ & 254 & 0.34 & 23.06 & 0.28 & 0.19 \\
\hline $1.00-2.00$ & 16 & 1.28 & 20.59 & 0.25 & 0.22 \\
\hline $2.00-3.00$ & 5 & 2.61 & 26.75 & 0.32 & 0.42 \\
\hline $3.00-4.00$ & 0 & 0 & 0.00 & 0.00 & 0 \\
\hline $4.00-5.00$ & 1 & 4.47 & 15.69 & 0.19 & 0 \\
\hline $5.00-6.00$ & 0 & 0 & 0.00 & 0.00 & 0 \\
\hline $6.00-7.00$ & 0 & 0 & 0.00 & 0.00 & 0 \\
\hline $7.00-8.00$ & 0 & 0 & 0.00 & 0.00 & 0 \\
\hline $8.00-9.00$ & 0 & 0 & 0.00 & 0.00 & 0 \\
\hline $9.00-10.00$ & 0 & 0 & 0.00 & 0.00 & 0 \\
\hline
\end{tabular}




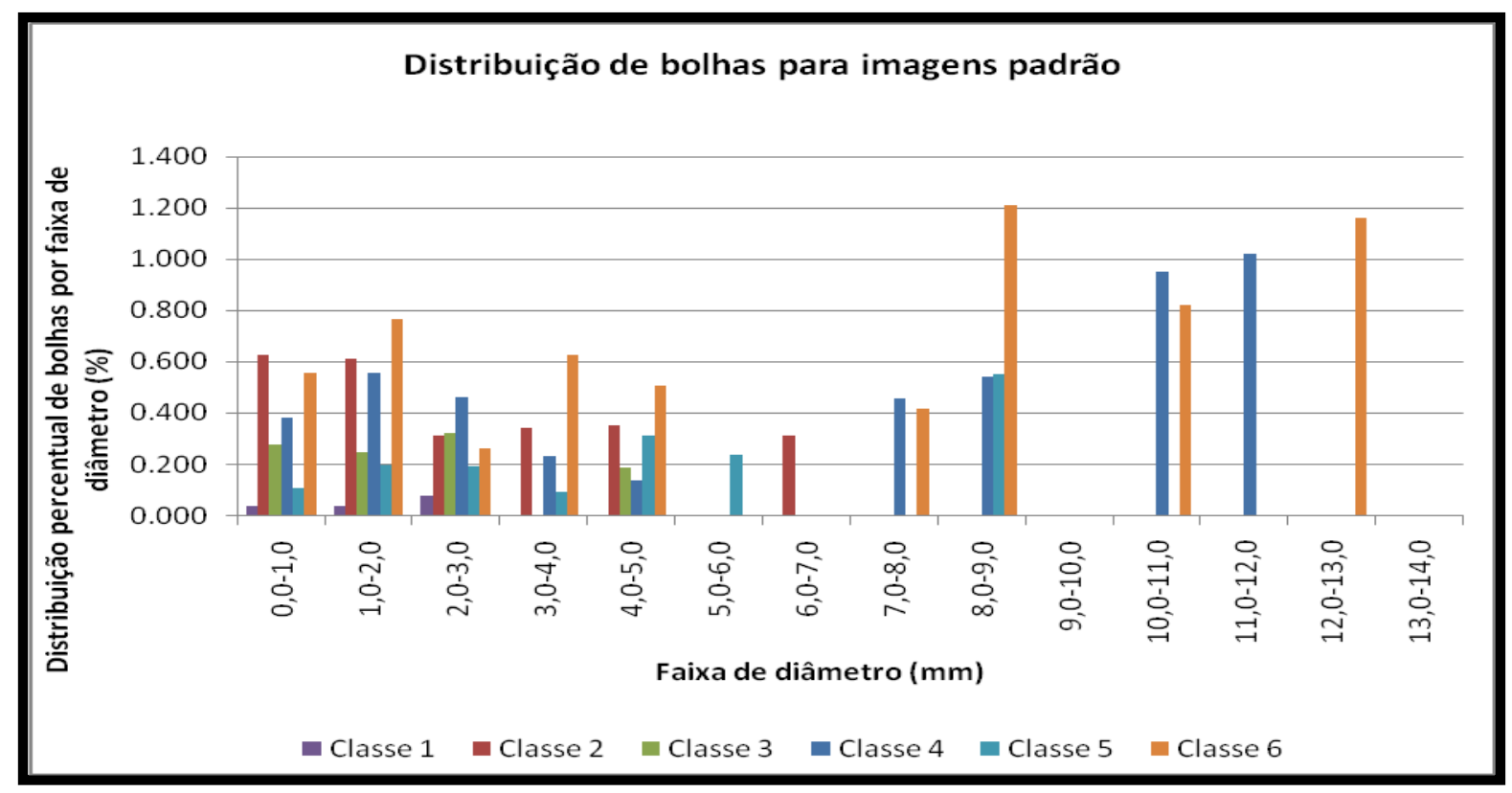

Figura 6 Gráfico relacionando as classes de classificação obtidas a partir de análise de imagens selecionadas como padrão. Sendo classe 1- excelente acabamento e classe 6 - péssimo acabamento.

A partir da análise das imagens padrão observou-se que a metodologia sugerida para o estudo é sensível as mudanças de acabamento e permite uma quantificação dos principais parâmetros envolvidos na classificação da qualidade do acabamento em peças pré-fabricadas de concreto.

Fez-se então a classificação das peças amostradas. Foram tratadas seis imagens por peça, os resultados são mostrados nas Figuras 7 e 8.

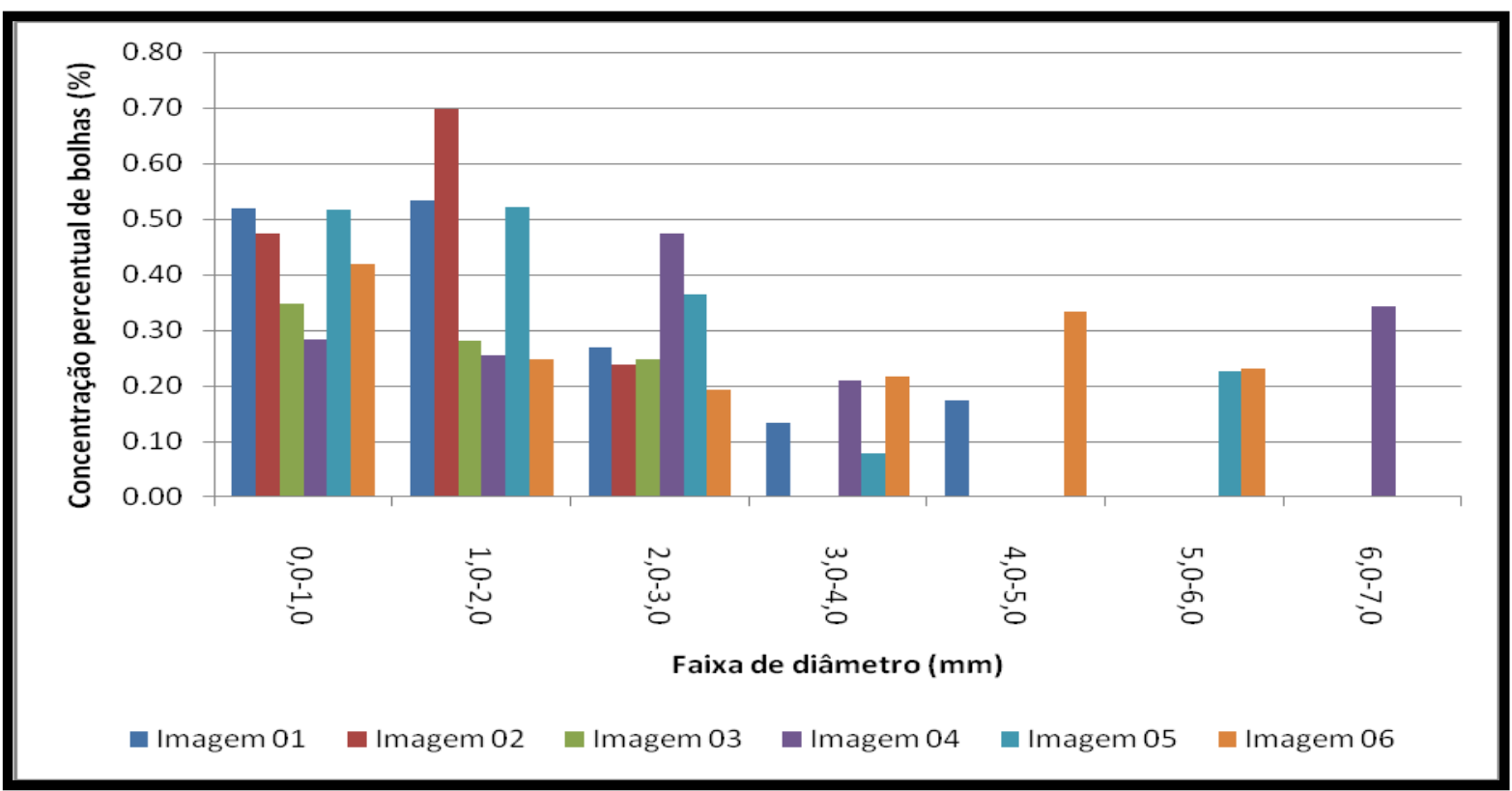

Figura 7 Valores para cada imagem obtida da peça produzida com concreto menos viscoso. 


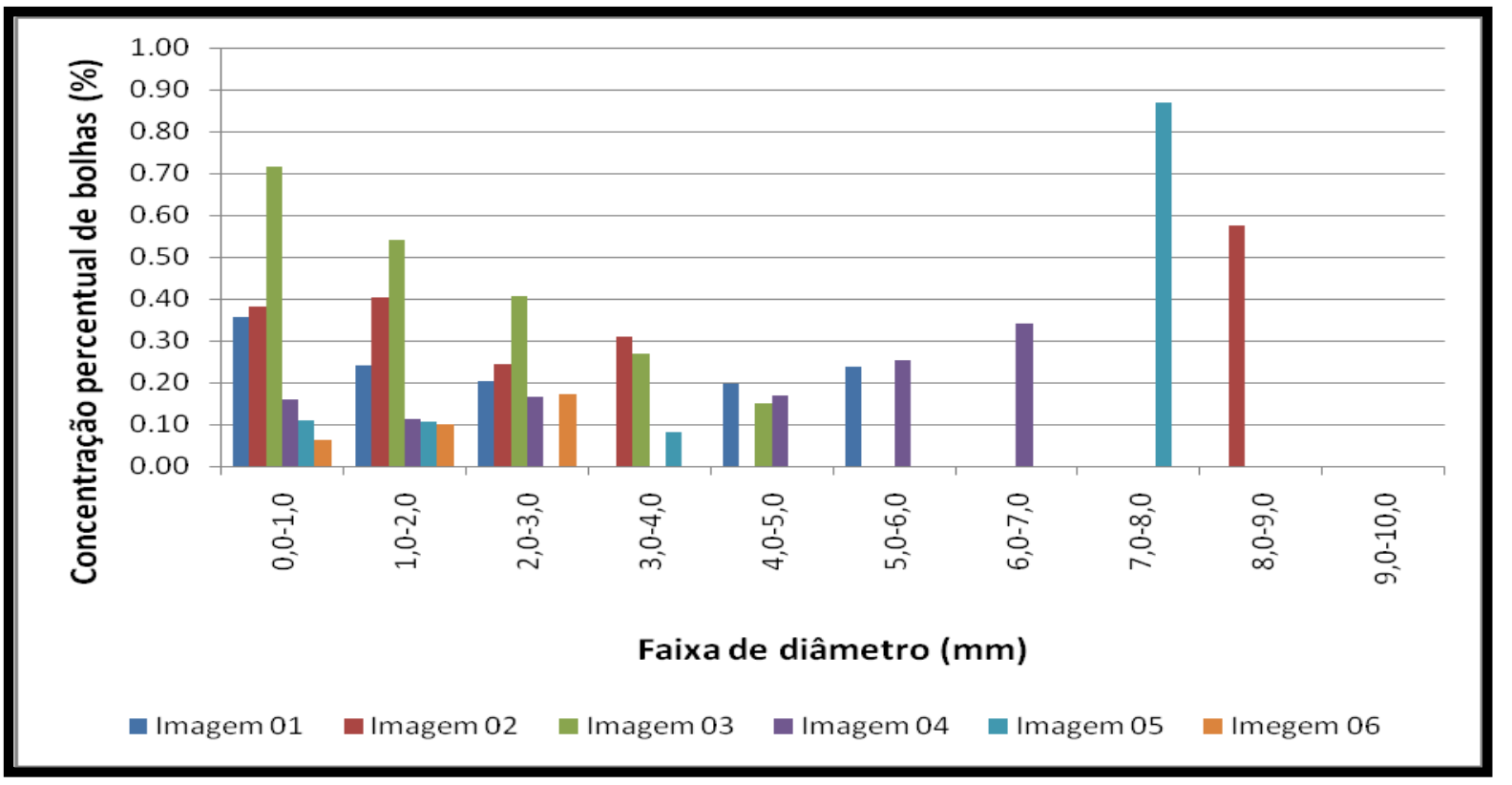

Figura 8 Valores para cada imagem da peça produzida com concreto mais viscoso.

O concreto menos viscoso, como esperado, apresentou uma concentração de bolhas com diâmetros menores. Isto se deve a maior facilidade de saída do ar aprisionado entre a forma e o concreto. Observa-se também a menor variabilidade da distribuição das bolhas entre as imagens, isto sugere que a peça produzida com concreto mais fluido apresentou um acabamento mais uniforme.

O concreto mais viscoso potencializa a retenção de bolhas de diâmetros maiores, pois exige mais esforço para que estas possam migrar para a superfície superior da forma possibilitando sua saída da peça. Por ser menos fluido o concreto 2 proporcionou uma retenção diferencial no diâmetro das bolhas sendo que a parte inferior da peça tende a apresentar um acabamento de melhor qualidade, enquanto a parte superior apresentou bolas de diâmetros maiores.

A partir das imagens individuais foi possível traçar uma distribuição média das bolhas para cada faixa de diâmetro, Figura 9. Esta distribuição média foi utilizada para classificar a qualidade do acabamento das peças. 


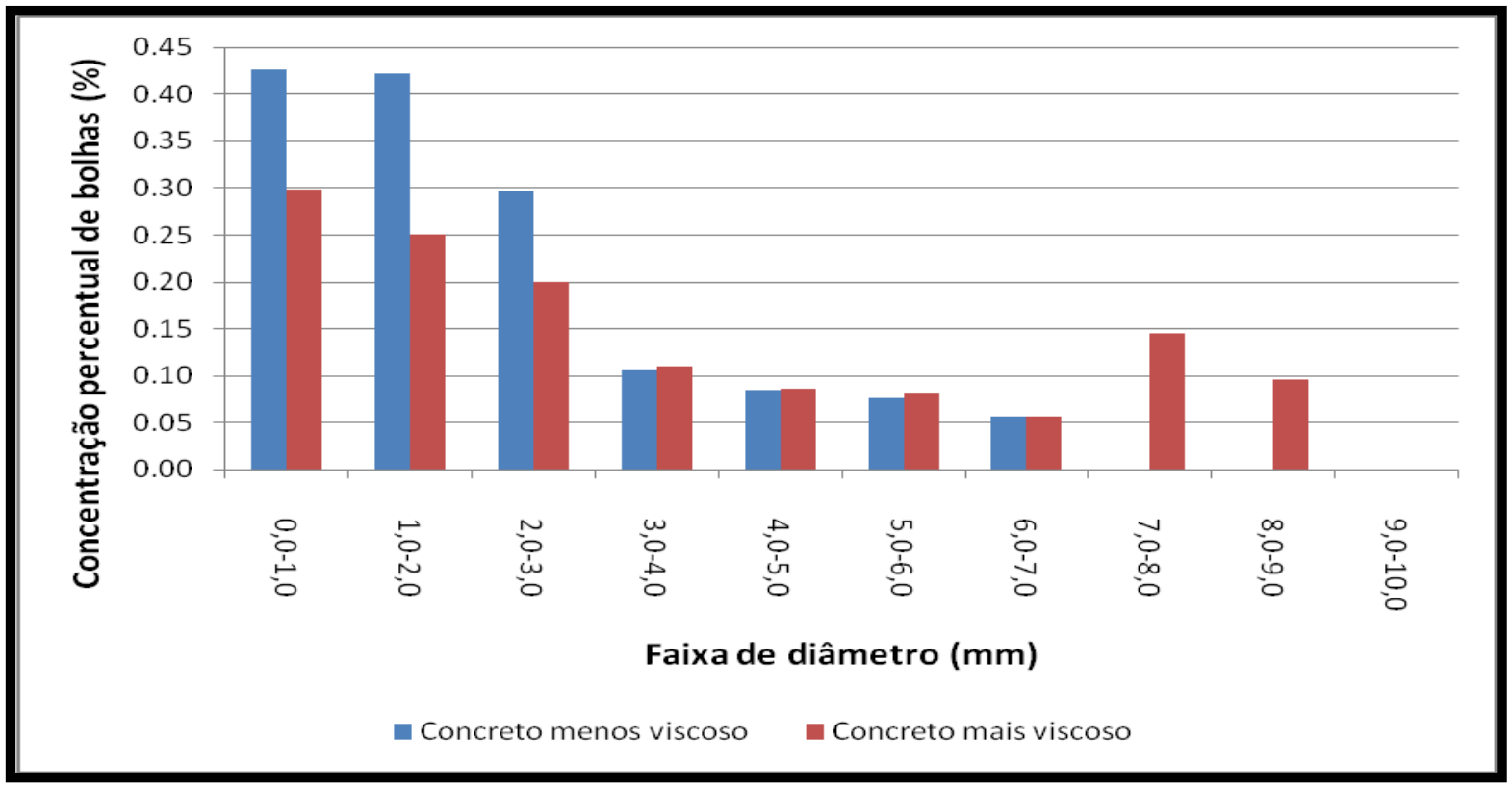

Figura 9 Comparação entre as distribuições médias de bolhas para cada tipo de concreto.

A partir da comparação com os parâmetros definido na Figura 6 as peças foram classificadas como classe 2 e classe 4 , para o concreto menos viscoso e mais viscoso, respectivamente.

\section{CONCLUSÕES}

A metodologia apresentada mostrou-se sensível as mudanças de acabamento de peças pré-fabricadas em concreto. Desta forma foi possível de forma relativamente simples classificar as peças de concreto produzidas a partir do padrão definido pelo Guide for surface finish of formed Concret (Hurd, 1999).

O diâmetro da bolha ou defeito é o parâmetro mais relevante para a definição do acabamento superficial de peças pré-fabricadas. Sendo a área ocupada por estes defeitos um fator que deve ser quantificado, porém de menor importância.

Pode-se diferenciar a homogeneidade do acabamento superficial da peça pela análise da variabilidade da concentração de bolhas para cada faixa de diâmetros.

A peça produzida com concreto menos viscoso apresentou melhor acabamento sendo classificada como classe 2, além disso observou-se uma maior homogeneidade em sua superfície, ou seja, um acabamento mais uniforme.

A peça produzida com concreto mais viscoso foi classificada como classe 4, por apresentar bolhas de maior diâmetro. Apresentou também grande variabilidade entre as imagens, o que indica variabilidade de acabamento, sendo que as bolhas de maior diâmetro encontram-se na parte superior da forma enquanto a parte inferior possui acabamento de melhor qualidade. 
Pode-se observar que a metodologia apresenta potencial de automatização o que tornaria o processo de inspeção de peças pré moldadas mais simples rápido e objetivo, reduzindo custos e melhorando a qualidade dos produtos finais.

\section{AGRADECIMENTOS}

Os autores gostariam de agradecer a empresa BPM Pré-moldados que forneceu o material e as instalações para que fosse possível a realização deste estudo.

\section{REFERÊNCIAS}

ABCIC - Associação Brasileira da construção industrializada de concreto Disponível em www.abcic.com.br. Acesso em 24/05/2011.

Annerel, E., Schutter, G. de (2007). Microstructure and Aesthetic Appearence of SCC. In: 5 International RILEM Symposium on Self-Compacting Concrete, Belgium.

El Debs, M. K. (2017). Concreto pré-moldado: fundamentos e aplicações. São Carlos: EESC-USP.

Filho, O. M., Neto, H. V.(1999). Processamento digital de imagem. Rio de Janeiro: Brasport.

Gonzales, R. C., Woods, R. E. (2000). Processamento de imagens digitais. Tradução Roberto Marcodes e Cesar Junior. São Paulo: Edgar Blucher.

Hurd, M., Schierhorn, C., Irace, M. (1999). Guide for Surface Finish of Formed Concrete. As-cast Strctural Concrete. Prepared by the ASCC(American Society of Concrete Construction), Education and training Committee.

Pieri, T. S. (2007). Concreto de Alto Desempenho Auto-Adensável (CADAA) para Estruturas PréFabricadas de Concreto. Monografia, Universidade Federal de Santa Catarina, Florianópolis, SC, Brasil.

Terzian, P. (2005). Concreto Pré-Fabricado in: Isaia, G.. Concreto Ensino, pesquisas e realizações. volume 2, cap 44, Editora IBRACOM.

Moreira, K. A. W. (2009). Estudo das manifestações patológicas na produção de pré-fabricados de concreto. Dissertação de mestrado, Universidade Tecnológica Federal do Paraná, Curitiba, PR, Brasil. 